\title{
Exploring Business Communication Strategies Based on CEFR
}

\author{
Yasuo Nakatani
}

\begin{abstract}
This study explores how international businesspeople recognize the required levels of English for business purposes. First five well-experienced international business experts were interviewed to investigate the use of relevant skills and communication strategies (CSs) to enhance their business negotiation. The results indicate that they tend to use advanced strategies for maintaining and developing their interaction. Next, an open-ended questionnaire study for $\mathbf{2 0 0}$ subjects using English for their work was conducted. The results reveal that higher level people in the CEFR tend to use $62 \mathrm{CS}$ items for their business. These items can be used to operate quantitative research in the future.
\end{abstract}

Index Terms-Business communication, communication strategies, interview, questionnaire.

\section{INTRODUCTION}

The Common European Framework of Reference for Languages (CEFR) has been used for the instruction and assessment of foreign languages in many countries. It is regarded as the useful guideline to describe achievements of learners of foreign languages across Europe [1]. As the Reference Levels of the CEFR was developed by focusing on European languages, it seems to be difficult for Japanese teachers to introduce the CEFR as it is. Therefore, the applicability of CEFR-J which is the modified version for Japanese EFL (English as a foreign language) learners has been explored [2], [3]. In particular, it is claimed that we need to develop the precise descriptions aiming at the Proficient User Levels such as C1: Effective Operational Proficiency, and C2: Mastery who need higher skills for the target language (TL) interaction. In order to negotiate in the TL, the necessity of communication strategies (CSs) has been pointed out [4], [5].

However, little research has investigated to identify the specific features of proficient users by both reliable and valid methods. In particular, previous researchers tend to use a questionnaire based on their intuition or personal experiences [6]. Unfortunately, there are few studies which developed questionnaire items by direct research methods such as interviews, and qualitative methods such as open-ended questionnaire studies in order to establish relevant survey items for further quantitative analysis. The aim of this study is to explore the usage of CSs for $\mathrm{C} 1$ and $\mathrm{C} 2$ levels of the CEFR though both interviews and a questionnaire study with international business experts.

Manuscript received April 15, 2016; revised September 14, 2016.

Yasuo Nakatani is with Faculty of Economics, Hosei University, Tokyo, Japan (e-mail: nakatani@ hosei.ac.jp).

\section{LITERATURE REVIEW}

It has been regarded that the CEFR describes in a comprehensive way what language learners have to learn to do in order to use a language for communication and what knowledge and skills they have to develop so as to be able to act effectively [1]. In particular, as seen in the following statement, in order to improve the TL skills, the CEFR suggests introducing communication strategy training focusing on metacognitive strategy development.

"The use of communication strategies can be seen as the application of the metacognitive principles: Pre-planning, Execution, Monitoring, and Repair Action to the different kinds of communicative activity: Reception, Interaction, Production and Mediation... Here what is meant is the adoption of a particular line of action in order to maximize effectiveness." (CEFR: LTS, p.15).

The CEFR also present some examples of CS use as interaction strategies as shown in the following Table I (CEFR: LTS, p. 85).

\begin{tabular}{|l|} 
TABLE I: COMMUNICATION STRATEGIES IN CEFR \\
\hline Planning \\
framing (selecting program) \\
identifying information/opinion gap (felicity conditions) \\
judging what can be presupposed \\
planning moves \\
Execution \\
taking the floor \\
co-operating (interpersonal) \\
co-operating (ideational) \\
dealing with the unexpected \\
asking for help \\
Evaluation \\
monitoring (schema, program) \\
monitoring (effect, success) \\
Repair \\
asking for clarification \\
giving clarification \\
communication repair \\
\hline
\end{tabular}

Although these examples may be useful for general ideas for CS use, they are too general to apply into business contexts. Also the number of studies which examined the applicability of such CSs for Japanese EFL learners is limited [7]. Moreover, one of the important goals of the CEFR is to enhance the TL for business contexts as follows:

"To deal with the business of everyday life in another country, and help foreigners staying in their own countries to do so." (CEFR: LTS, p. 3). 
Therefore, it is essential to examine what kinds of CSs EFL learners should learn for future business purposes and how such strategies should be integrated into current teaching programs.

However, surprisingly there is little research conducting a statistical method by using reliable question items in order to investigate business CSs for EFL learners [8], [9]. Because of the lack of reliable and valid investigation schemes to assess strategies for business communication, it has, to date, been difficult to examine accurately which strategies affect interactional ability.

To answer these significant questions, as the first step, this study investigates how international businesspeople recognize the required levels of English and CS usage for business interaction and negotiation.

First, a precise interview study was conducted to explore how CEFR-C level business people recognize their CSs in authentic contexts. Then an open-ended questionnaire study was operated to reveal significant strategy concepts shared by high level speakers of English.

\section{Methodology}

\section{A. Interview Study}

It is claimed that interviewing participants can provide useful data. In the interviews, they can take time and report on their business behaviors in English [10]. For example, they might list the skills that they employed when speaking with a native English speaker. It can be assumed that this kind of procedure, to some extent, enables researchers to understand participants' intentions to use particular strategies in business negotiation contexts. Such detailed qualitative information is difficult to obtain by other data collecting methods such as observation.

The method of dada collecting followed previous representative studies in this field [8], [9]. Five well-experienced international business experts were interviewed to investigate the use of relevant communicative skills and CSs to enhance their business interaction (see, Table II).

\begin{tabular}{|c|c|c|}
\hline \multicolumn{3}{|c|}{ TABLE II: PARTICIPANTS' INFORMATION } \\
\hline $\begin{array}{l}\text { Place of } \\
\text { interview }\end{array}$ & Job title & Years of service overseas \\
\hline London & IT Consultant & 20 years, UK \\
\hline London & HR Consultant & 20 years, UK \\
\hline Oxford & Lawyer & 4 years, US, 2 years, UK \\
\hline 4 Tokyo & Manager & 4 years, US 6 years, \\
\hline 5 Tokyo & Manager & 3 years, Saudi Arabia, 7 years, US \\
\hline
\end{tabular}

The individual interviews in both English and Japanese lasted approximately one hour. They were encouraged to report regarding the following three aspects: outline of their work, required English communication skills, and the use of CSs for their business purposes. The interviews were recorded on audio and videotape, which were transcribed and then analyzed as corpus data. The focus is on when they need CSs and what kinds of CSs they use.

Although it is possible to obtain rich data for CSs by interviewing method, there are several disadvantages of interviewing. For example, the data is inevitably subjectively reported by the participants. Interviews can cost time and money. Interviewing skills and techniques of investigators also affect participants' reaction to the questions. It is not easy to obtain concrete evidence of particular strategy use by an interview method alone. Therefore, we still need other objective data to validate the result of the interview. For example, in order to elicit data from a large number of subjects, a written questionnaire method is an ideal approach. It also saves money and time.

\section{B. Questionnaire Study}

To validate the results of the interview study, an open-ended questionnaire was administered to a total of 200 subjects who used English for daily business. They attended a business case study work shop lead by the author in Tokyo in 2014. Sixty percent of the participants were male and forty percent of them were female.

They were asked to complete statements such as "When I am speaking English in business contexts, I pay attention to ....," "When I am listening to other people speaking English in business contexts, I try to . ..," and "What helps me most when I negotiate with others in English ...."

These items were designed to elicit a variety of strategies for oral communication. The participants wrote answers in English within 15 minutes.

\section{RESUlts 1: INTERVIEW STUDY}

\section{A. When Do They Use Communication Strategies?}

Some participants reported the need of CSs when they were involved in difficult contexts such as making and expiring new contracts, or dealing with lawsuits (ID 1, 3, 5). When facing decision-making situations, they were required to use CS appropriately (ID 1,2). They pointed out the necessity of CS for coping with different business culture. (ID 1, 2, 5). For instance, during their overseas services, Japanese businesspeople are supposed to adjust to western business styles such as voluntarily risk-taking behaviours. They have to respect the western individualism rather than the group-oriented value which has been emphasised in Japanese business culture. Also they should pay attention to provide equal opportunities to all employees and enhance affirmative actions which tend to be neglected in Japanese companies.

\section{B. What Kinds of Communication Strategies Do They Use?}

As shown in Table III, there were 8 types of strategies they frequently used. The analysis of the corpus revealed that the participants tended to make longer utterances and use substantial achievement strategies, such as modified interaction, modified output, time-gaining and response for maintenance strategies. Accordingly, they were aware of using specific strategies to improve their interaction. They attempted to overcome cultural differences and were eager to negotiate with their counterparts. It can be concluded that acquiring and using CSs is essential for future business leaders who operate oversea services. 


\section{TABLE III: CS USAGE IN BUSINESS CONTEXTS}

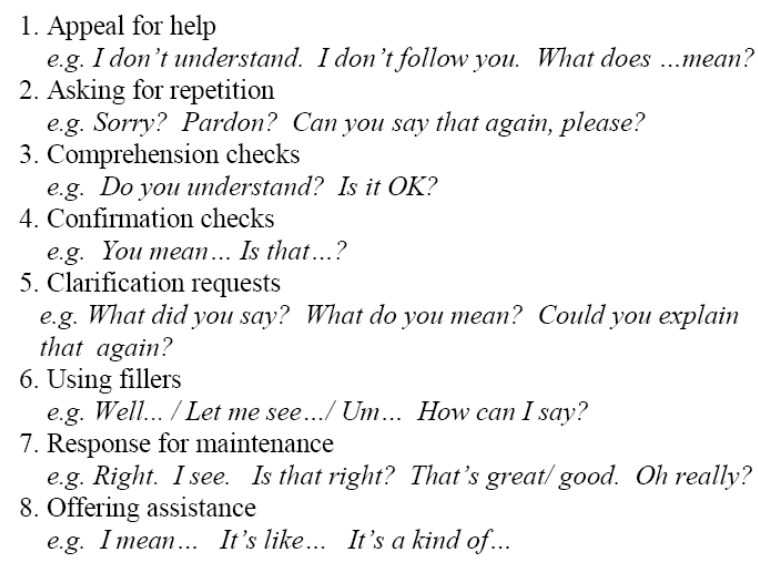

\section{RESULTS 2: OPEN-ENDED QUESTIONNAIRE AND DEVELOPING A RELIABLE SURVEY INSTRUMENT}

After collecting all questionnaires from the participants, the author analyzed the descriptive data manually. The results indicate that there were 170 strategy items elicited by the 200 participants who used English for business purposes.

These items were compared with the results of the interview study. Then they were categorized into 62 strategies by the procedures presented in previous studies [11], [12]. Table IV shows the results. They can be regarded as valid CS items for business communication used by CEFR-C level learners.

\section{TABLE IV: Cs USED BY CEFR C-LEVEL}

1. I don't mind if I can't understand every single detail during the conversation.

2. I speak without considering the possible consequences.

3. I solve problems using a step-by-step approach.

4. I take into consideration of interlocutors' position of the company.

5. I say what I think, simply and directly.

6. I take actions based on careful thought and analysis.

7. I take time for preparation and implementation before meetings.

8. I regularly question people about their basic assumptions.

9. I try to create friendly atmosphere during meetings.

10. I pay attention to interlocutors' time-management habits based on their culture.

11. I avoid disorganized things and prefer to fit things into a coherent pattern.

12. I like to relate my actions to a general principle of the company.

13. In discussions I like to get straight to the point.

14. I tend to have distant, rather formal, relationships with people at work.

15. I thrive on the challenge of tackling something new and different.

16. I pay attention to detail before coming to a conclusion.

17. I prefer to have as many sources of information as possible.

18. I listen to other people's points of view before putting my own forward.

19. I tend to be open about how I'm feeling.

20. In discussions I enjoy argument with the other participants.

21. I prefer to respond to events on a spontaneous, flexible basis.

22. It worries me if I have to rush a piece of work to meet a tight deadline.

23. I tend to judge people's ideas on their practical merits.

24. I guess the speaker's intention based on what he/she has said so far

25. I make decisions based on a thorough analysis rather than my intuition.

26. In discussions I usually produce lots of spontaneous ideas.

27. In meetings I put forward practical, realistic ideas.

28. I prefer to stand back from a situation and consider all the perspectives.
29. I can often see inconsistencies and weaknesses in other people's arguments.

30. I talk more than I listen during the interaction.

31 . I try to propose better, more practical ways to get things done.

32. I think written reports should be short and to the point.

33. I anticipate what the speaker is going to say based on the context.

34. I tend to discuss specific things with people rather than engaging in social discussion.

35. In discussions I get impatient with irrelevancies and digressions.

36. I tend to produce lots of drafts before settling on the final report.

37. I like to ponder many alternatives before making up my mind

38. In discussions with people I try to be dispassionate and objective.

39. I tend to relate current actions to a longer term bigger picture.

40. I pay attention to interlocutors' cultural background.

41. I do the listening rather than the talking during the interaction.

42. I do whatever is relevant to get the job done.

43. I pay attention to what people think.

44. I change my way of saying things according to the context in order to continue communication.

45. I take my time to express what I want to say.

46. I try to speak clearly and loudly to make myself heard.

47. I make comprehension checks to ensure the listener understands what I want to say.

48. I repeat what I want to say until the listener understands.

49. While speaking, I pay attention to the listener's reaction to my speech.

50. I give examples if the listener doesn't understand what I am saying

51. I ask for repetition when I can't understand what the speaker has said.

52. I make a clarification request when I am not sure what the speaker has said.

53. I ask the speaker to use easy words when I have difficulties in comprehension.

54. I ask the speaker to slow down when I can't understand what the speaker has said.

55. I make clear to the speaker what I haven't been able to understand.

56. I use circumlocution to react to the speakers' utterance when I don't understand their intention well.

57. I ask the speaker to give an example when I am not sure what he/she has said.

58. When other people behave in a way that I don't understand, I ask them why they are doing this.

59. In conversations with speakers of other languages I avoid unclear or ambiguous words.

60. I try to understand interlocutors' requirements, attitudes and behaviours

61. I manage interlocuors' demand and monitor their satisfaction

62. I try to attract appropriate staff and employees.

\section{CONCLUSION AND IMPLICATIONS}

It has been argued that the use of specific CSs is essential to negotiate with business counterparts from different cultural backgrounds [13]. However, there are few guidelines to present authentic goals regarding how to develop such negotiation skills for EFL learners.

It is claimed that the CEFR could be used for the instruction and assessment of foreign languages learning. It is the useful guideline to see the levels of learners. However, there is little research which investigated the use of business CSs by valid and reliable methods.

Accordingly, this paper focused on how valid information about perception of higher-levels in CEFR for strategy use during business communication could be gathered systematically. The study attempted to develop a reliable questionnaire for future statistical analysis. 
The results of detailed interview study indicate there are 8 types of CS used by 5 business experts. These strategies were compared with the lists of the open-ended questionnaire study dealing with 200 businesspeople using English on a daily basis. Based on these results, it is found that there are $62 \mathrm{CS}$ items for business purposes. By using these valid items, it is possible to conduct a reliable statistical approach examining CS use by the higher level of learners in the CEFR. For instance, by developing a Likert-type questionnaire using these 62 items, we can conduct a large scale survey and analyze the data by the factor analysis. Then we will be able to obtain a reliable and valid survey instrument for further research examining business communication strategies.

Although this kind of survey instrument is applicable in actual communicative events in order to elicit reported strategy use from EFL learners, further in-depth investigations are needed to assess the precise nature of CS use in Business. For example, in this study there is no discussion of how the gender of the participants might have affected their use of CSs in interactional tasks. Given that the gender of participants plays an important role in their use of strategies [14], [15], this limitation must be borne in mind. It is also important to investigate the effect of many types of communicative tasks on self-reported learner strategy use.

There are some pedagogical implications from this study. We may say that Japanese EFL students should be exposed to the CSs more and should be encouraged to use them in their daily classroom conversations [16]. As most of them will use CSs in actual business contexts, it is important to develop a specific teaching program based on such strategies [17]. Teachers should introduce various types of CSs and raise learners' awareness of their effectiveness. In order to achieve these goals, as previous research suggests [4], [18], [19], it can be beneficial to introduce meta-cognitive training to solve problems and develop interaction in English [20], [21]. It may be a good idea to introduce authentic business textbooks based on real case studies of specific companies which could encourage students to solve business assignments with other students [22], [23].

\section{ACKNOWLEDGMENT}

This research was supported by Grant-in-Aid for Scientific Research (Project Number: 26370743; Principle investigator: YASUO NAKATANI: 90290626).

\section{REFERENCES}

[1] Common European Framework of Reference for Languages: Learning, teaching, assessment (CEFR : LTS) (2001), Cambridge: Cambridge University Press.

[2] I. Koike et al., Grant-in-Aid for Scientific Research Project, 2008.

[3] M. Negishi, "How much do we have in common with the Common European Framework of Reference? - The applicability of the CEFR to an IRT-based English proficiency test in Japan," Readings in Second Language Pedagogy and Second Language Acquisition in Japanese Context, pp. 83-100, 2006.

[4] A. D. Cohen, Strategies in Learning and Using a Second Language, Essex: Longman, 1998.
[5] Y. Nakatani, and C. C. Goh, "A review of oral communication strategies: focus on interactionist and psycholinguistic perspective," In Language Learner Strategies, A. D. Cohen \& E. Macaro, Eds. Oxford: Oxford University Press, 2007, pp. 207-227.

[6] M. Guffey, Business Communication, Process and Product, Mason, $\mathrm{OH}$ : South-Western Cengage Learning, 2008.

[7] Y. Nakatani, Improving Oral Proficiency through Strategy Training: Focus on Language Testing, Learners' Corpus and Cognition, Deutschland: LAP Lambert Academic Publishing, 2010b.

[8] Y. Nakatani, "Applicability of the strategy inventory for language learning (SILL) to a communicative task for Japanese EFL learners," Bulletin of Nakamura Gakuen University, vol. 38, pp. 79-86, 2006.

[9] Y. Nakatani, "Developing an oral communication strategy inventory," The Modern Language Journal, vol. 90, no. 2, pp. 151-168, 2006.

[10] J. M. O'Malley, A. U. Chamot, G. Stewner-Manzares, R. P. Russo, and L. Kupper, "Learning strategies applications with students of English as a second language," TESOL Quarterly, vol. 19, pp. 557-84, 1985.

[11] X-H. Huang, and M. Naerssen, "Learning strategies for oral communication," Applied Linguistics, vol. 8, pp. 287-307, 1987.

[12] R. L. Politzer, "An exploratory study of self-reported language learning behaviors and their relation to achievement," Studies in Second Language Acquisition, vol. 6, pp. 54-67, 1983.

[13] Y. Nakatani, M. Makki, and J. Bradley, "Free to choose: Communication strategy use in EFL classrooms in Iran," Iranian Journal of Applied Linguistics, vol. 15, no. 2, pp. 61-84, 2012.

[14] M. J. Green and R. Oxford, "A closer look at learning strategies, L2 proficiency, and gender," TESOL Quarterly, vol. 29, pp. 261-297, 1995.

[15] R. L. Oxford and M. Nyikos, "Variables affecting choice of language learning strategies by university students," The Modern Language Journal, vol. 73, pp. 291-300, 1989.

[16] E. Macaro, Y. Nakatani, Y. Hayashi, and N. Khabbazbashi, "Exploring the value of bilingual language assistants with Japanese English as a foreign language learners," The Language Learning Journal, vol. 20, pp. 1-14.

[17] Y. Nakatani, "Motivating EFL students: Focus on oral and written communication strategies," JACET Summer Seminar Proceedings, vol. 12, pp. 11-15, 2014.

[18] Y. Nakatani, "The effects of awareness-raising training on oral communication strategy use," The Modern Language Journal, vol. 89, no. 1, pp. 76-91, 2005.

[19] Y. Nakatani, "Identifying strategies that facilitate EFL learners' oral communication: A classroom study using multiple data collection procedures," The Modern Language Journal, vol. 94, no. 1, pp. 116-163, 2010.

[20] Y. Nakatani, "Innovative strategies in the confectionery industry: A case study approach evaluating brand leadership in a regional market," Tokyo University of Science Kiyo, vol. 40, pp. 183-202, 2008.

[21] Y. Nakatani, "The dynamics of leadership and organizational change in the brewing industry," Tokyo University of Science Kiyo, vol. 41, pp. 471-487, 2009.

[22] Y. Nakatani, "Investigating criterial features of EFL textbooks based on the CEFR," Journal of International Scientific Publication: Educational Alternatives, vol. 11, no. 2, pp.183-189, 2013.

[23] Y. Nakatani and R. Smithers, Global Leadership: Case Studies of Business Leaders in Japan, Tokyo: Kinseido, 2015.

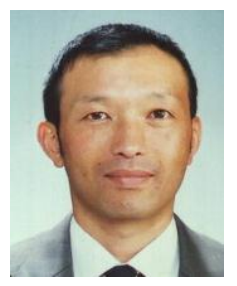

Yasuo Nakatani is a professor of the Faculty of Economics at Hosei University. He received $\mathrm{PhD}$ from University of Birmingham and was a visiting scholar at University of Oxford. He published a number of research articles regarding communication strategies in international Journals such as The Modern language Journal $(M L J)$. He is a coauthor of Language Learner Strategies: Thirty Years of Research and Practice form Oxford University Press and has published several books such as Improving Oral Proficiency through Strategy Training. He is a reviewer of MLJ, TESOL Quarterly, System, Language Learning and Journal of Pragmatics. 